\title{
Analytical Methods for Temperature Field and Temperature Stress of Column Pier under Solar Radiation
}

\author{
Yin-hui Wang, ${ }^{1}$ Yi-song Zou, ${ }^{2}$ Cheng-jun $\mathrm{Li}^{2}{ }^{2}$ Lue-qin $\mathrm{Xu}^{2}$, and Shi-chun Wang ${ }^{3}$ \\ ${ }^{1}$ Ningbo Institute of Technology, Zhejiang University, Ningbo, Zhejiang 315100, China \\ ${ }^{2}$ School of Civil Engineering and Architecture, Chongqing Jiaotong University, Chongqing 400074, China \\ ${ }^{3}$ China Huaxi Engineering Design \& Construction Co., Ltd., Chongqing Branch, Chongqing 400039, China \\ Correspondence should be addressed to Lue-qin Xu; 272310232@qq.com
}

Received 15 September 2014; Accepted 27 January 2015

Academic Editor: Chenfeng Li

Copyright (C) 2015 Yin-hui Wang et al. This is an open access article distributed under the Creative Commons Attribution License, which permits unrestricted use, distribution, and reproduction in any medium, provided the original work is properly cited.

Based on the previous research work, a new idea is proposed for analyzing the impact of solar radiation on the substructure of bridges. Investigation is conducted in the thermodynamic phenomena and temperature stress of a dual-column pier. Research is led to the thermal conductivity of concrete structure and the values of the environmental parameters under solar radiation. An analytical code is written for the thermal analysis of the dual-column pier using the parametric modeling function of FE software, by means of which the temperature distribution of the bridge structure is computed under solar radiation. Using the thermal analytical results, the temperature stress of the dual-column pier is further calculated. The results tell that the temperature gradient distribution curve inside the concrete of the pier fits favorably the curve defined in the design specification and coincides quite well with real situation, which verifies the new idea proposed in this paper. Under the solar radiation which is a time-variable nonlinear temperature load to the bridge, the maximum principal stress is found at the corner of the pier with the sign of negative, which is believed to threaten the safety of the substructure of bridge and is necessary to arouse emphasis.

\section{Introduction}

Solar radiation induces transient variation of temperature stress in the bridge structures, and this nonlinear temperature stress which is time-variable tends to bring about a potential safety hazard to the bridge structure. According to some reports, it can be found that the solar radiation may be one of the reasons to blame for the failure of some bridges $[1,2]$. And hence prediction of the stress levels due to the timevariable solar radiation loads is of fundamental relevance in the correct design of bridge structures considering the aspects of the maximum stress limitation and the durability of constructions $[3,4]$. The variable temperature distribution in concrete bridge structures has attracted a lot of research interests, since interaction with the external temperature and the solar radiation leads to seasonal and daily temperature gradient in the structure $[5,6]$. So far the majority of the efforts have been made in the influence of solar radiation on the bridge superstructure. And research works have been devoted to the temperature stress variation of reinforced concrete girders under solar radiation, especially reinforced concrete box girders [7-9]. Until now, however, little work has been done in the sensitive analysis of the solar thermal effects on the bridge substructures. In this paper, temperature field and temperature stress are analyzed for the bridge substructure under the time-variable and space-variable thermal loads. A dual-column pier is taken as an illustrative example and an analytic train of thought is proposed.

As shown in Figure 1, the first step in the process of analysis is to determine the environmental parameters of solar radiation for the bridge substructure, the second step is to conduct thermal effect analysis of a FE model to acquire the distribution of surface temperature of the bridge substructure using the environment parameters defined in the first step, and the next step is to perform a force analysis of the bridge substructure using the temperature distribution as the input of load, and finally engineering suggestions are proposed based on the analytical results. 


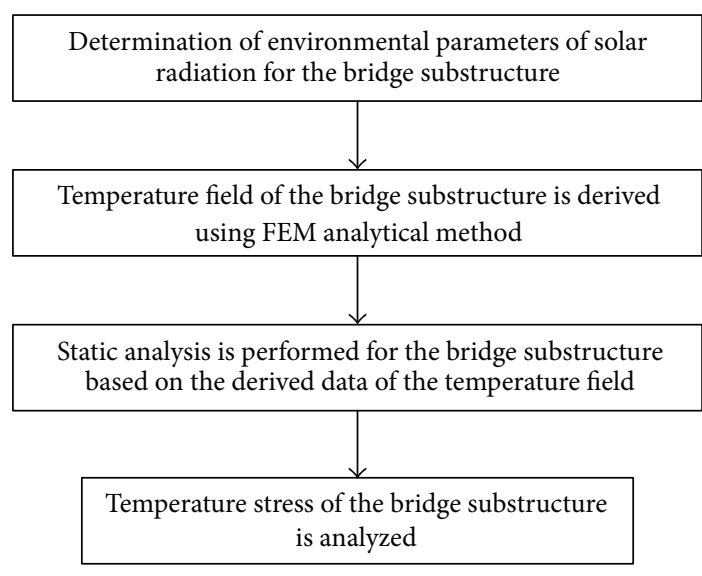

FIGURE 1: Flowchart of the analytical thought.

\section{Discussion of Thermodynamic Parameters for the Bridge Substructure}

To accurately analyze the temperature effect on the reinforced concrete bridge piers under the solar radiation, it is necessary to choose a reasonable method to obtain the temperature field of the bridge pier. And the thermodynamic parameters need to be determined firstly. Obviously, the temperature field of the reinforced concrete pier changes as the solar radiation varies in a day. The time-varying temperature field of the concrete pier is closely related to the material properties and some surroundings influence factors, such as the geographical position and orientation of the pier system, the intensity of the solar radiation, the heat exchange coefficient, the atmosphere temperature, and the environment in which the pier system locates.

2.1. Heat Exchange Coefficient $\alpha$. The heat exchange coefficient, also known as natural convection heat transfer coefficient, is defined to account for the amount of heat that is transferred between materials and objects (whether in gaseous state or in liquid state or in solid state) which have different temperatures [10]. The illustrated bridge substructure is constructed of concrete which located in natural environment. Under the sunshine, two dependent thermal exchanges, taking place on the surfaces of the bridge substructure, are induced, respectively, by solar radiation and by heat conductivity and convection. The thermal exchange component induced by solar radiation, which is of clear physical significance, can be referred to as heat exchange coefficient by solar radiation $\alpha_{s}$. The influences of heat conductivity and heat convection can be combined in calculation and designated as the convective heat exchange coefficient $\alpha_{k}$. In practical engineering, these two components can be combined as a total thermal exchange coefficient $\alpha$ :

$$
\alpha=\alpha_{s}+\alpha_{k}
$$

The heat exchange coefficient by solar radiation $\alpha_{s}$ changes as time and the pier surficial temperature change. Its peak value can be found during 12 14 o'clock, with a magnitude of around $5.0 \mathrm{w} /\left(\mathrm{m}^{2} \cdot{ }^{\circ} \mathrm{C}\right)$. For engineering purpose, the
TABLE 1: Average values of thermal exchange coefficient with the wind velocity $v=1.0 \mathrm{~m} / \mathrm{s}$.

\begin{tabular}{lccc}
\hline $\begin{array}{l}\text { Orientation of bridge } \\
\text { components }\end{array}$ & $\begin{array}{c}\alpha_{s} \\
\mathrm{w} /\left(\mathrm{m}^{2} \cdot{ }^{\circ} \mathrm{C}\right)\end{array}$ & $\begin{array}{c}\alpha_{k} \\
\mathrm{w} /\left(\mathrm{m}^{2} \cdot{ }^{\circ} \mathrm{C}\right)\end{array}$ & $\begin{array}{c}\alpha \\
\mathrm{w} /\left(\mathrm{m}^{2} \cdot{ }^{\circ} \mathrm{C}\right)\end{array}$ \\
\hline $\begin{array}{l}\text { On the surface exposed } \\
\text { to the sun }\end{array}$ & 3.9 & 7.1 & 11.0 \\
$\begin{array}{l}\text { On the surface in the } \\
\text { shade }\end{array}$ & 4.0 & 7.5 & 11.5 \\
\hline
\end{tabular}

coefficient $\alpha_{s}$ can be taken as $4.0 \mathrm{w} /\left(\mathrm{m}^{2} \cdot{ }^{\circ} \mathrm{C}\right)$ for the external surface analysis.

Convective heat exchange coefficient $\alpha_{k}$ is pertinent to the wind velocity. When the wind velocity is smaller than $5.0 \mathrm{~m} / \mathrm{s}$, the coefficient $\alpha_{k}$ can be obtained using the following equation:

$$
\alpha_{k}=5.8+4.0 v
$$

From (2), it can be found that when the thermal exchange coefficient plays a most dangerous role, the wind velocity is zero. But this situation only happens in the night, and it is not in conformity with the actual situations. The wind velocity and orientation are affected by many accidental factors. For civil engineering analysis, it is commonly accepted that using a constant wind velocity in calculation is deemed as conservative. In order to get a worst case in prediction of the maximum temperature stress, the wind velocity can be assumed to be a constant of $1.0 \mathrm{~m} / \mathrm{s}$. In Table 1 , the average thermal exchange coefficients are listed for different orientation of the pier surface where the wind velocity is assumed to be $1.0 \mathrm{~m} / \mathrm{s}$.

In the perspective of civil engineering calculations, the values of thermal exchange coefficients listed in Table 1 are of high reliability, for they are all conservative. But if comparison between theoretical calculation and field measurement is performed, an accurate value is quite necessary for the heat exchange coefficient.

2.2. Thermophysical Characteristic of Concrete. To obtain the temperature field, some thermophysical parameters need to be determined for the material of concrete, including the heat conductivity coefficient, the specific heat capacity, and the linear expansion factor. The main factor that has a notable influence on the thermal parameters (such as the heat conductivity coefficient and the specific heat capacity) of the concrete material is the mixing proportion. With regard to the normal weight concrete, the heat conductivity coefficient is within the limits of $1.86 \sim 3.49 \mathrm{~W} /\left(\mathrm{m} \cdot \mathrm{s} \cdot{ }^{\circ} \mathrm{C}\right)$, and the specific heat capacity is ranged in $800 \sim 1200 \mathrm{~J} /\left(\mathrm{kg} \cdot{ }^{\circ} \mathrm{C}\right)$. The linear expansion factor usually remains constant under the normal atmospheric temperature, and the value of $1.0 \times 10^{-5} /{ }^{\circ} \mathrm{C}$ can be used for normal weight concrete, reinforced concrete, and also prestressed concrete during the regular engineering calculation.

2.3. Calculation of Concrete Surficial Temperature under Solar Radiation. The amount of solar radiation on the ground 
TABLE 2: Atmospheric temperature collected at site $T_{a}$.

\begin{tabular}{lcccccrr}
\hline Collection time & $6: 00$ & $8: 00$ & $11: 00$ & $12: 30$ & $14: 30$ & $17: 00$ & $18: 00$ \\
\hline Atmospheric temperature $\left({ }^{\circ} \mathrm{C}\right)$ & 13.2 & 16.4 & 32.1 & 34.3 & 36.6 & 28 & 20.4 \\
\hline
\end{tabular}

TABLE 3: Typical values for the solar radiation intensity $j$ in the summer of Chongqing area $\left(\mathrm{w} / \mathrm{m}^{2}\right)$.

\begin{tabular}{lcccccccccc}
\hline \multirow{2}{*}{ Region } & Orientation & \multicolumn{9}{c}{ Local time } \\
& & 6 & 7 & 8 & 9 & 10 & 11 & 12 \\
\hline \multirow{3}{*}{ Chongqing, China } & $\mathrm{S}$ & 16 & 47 & 79 & 119 & 200 & 252 & 270 & 252 \\
& $\mathrm{~W}(\mathrm{E})$ & 16 & 47 & 79 & 104 & 122 & 133 & 138 & 340 \\
& $\mathrm{~N}$ & 124 & 153 & 131 & 104 & 122 & 133 & 138 & 133 \\
& $\mathrm{H}$ & 81 & 270 & 487 & 686 & 844 & 945 & 980 & 945 \\
\hline
\end{tabular}

$\mathrm{E}, \mathrm{S}, \mathrm{W}, \mathrm{N}$, and $\mathrm{H}$ refer to the vertical planes, respectively, normal to the eastern direction, the southern direction, the west direction, and the northern direction, and the horizontal plane.

surface is influenced by the angle of the sunlight and the cloud coverage. When the sunlight angle is small (in the morning or at the nightfall), the distance of sunlight travelling in the air is much farther, and therefore the amount of energy dissipated during travelling is much larger. In the meantime, if the cloudiness is increased, the sunlight energy is lost at a larger rate. The amount of energy reaching the surface of an object is also affected by the incidence angle of the sunlight. The surficial temperature of concrete structure under solar radiation can be obtained by

$$
T_{f}=T_{\alpha}+\frac{R}{\beta},
$$

where $T_{f}$ refers to the surficial temperature of concrete structure $\left({ }^{\circ} \mathrm{C}\right), T_{a}$ is the atmosphere temperature $\left({ }^{\circ} \mathrm{C}\right), \beta$ is convective heat exchange coefficient $\mathrm{w} /\left(\mathrm{m}^{2}{ }^{\circ} \mathrm{C}\right)$ and it can be taken as $\beta=50 \mathrm{w} /\left(\mathrm{m}^{2} \cdot{ }^{\circ} \mathrm{C}\right)$ for concrete structure, and $R$ designates the amount of solar heat that is absorbed by the structure $\left(\mathrm{w} / \mathrm{m}^{2}\right)$ and it can be written as $R=a_{1} \times j$, where $a_{1}$ represents the absorption coefficient on the structure surface and $j$ represents the solar radiation intensity on the structure surface $\left(\mathrm{w} / \mathrm{m}^{2}\right)$.

The atmospheric temperature adopted in the model calculation is chosen from a series of data collected at a site in Chongqing, which can represent the typical atmospheric temperature in one day. Table 2 lists the time in the day when the temperature data are collected and the corresponding time-varying atmospheric temperature at that particular time.

The absorption coefficient on the concrete structure surface is taken as $a_{1}=0.74$.

In Table 3, some typical values for the solar radiation intensity $j$ are listed, according to the observed data in the summer of Chongqing area.

\section{Calculation of Distribution of the Structural Surficial Temperature under the Solar Radiation}

3.1. Analytical Flowchart for Calculation of Temperature Field. Based on the theory of solar radiation [11], ANSYS/Mechanical is used to establish the parametric models including the environmental factors of the bridge pier under solar radiation.

APDL scripts are compiled from the total analytical process based on the code of ANSYS, and the temperature field is analyzed by addition of convectional boundary conditions on the elements. Figure 2 shows the details of the analytical flowchart.

3.2. Analytical Model for a Dual-Column Pier. For illustrative purpose, the substructure of the example bridge is a dualcolumn pier, and the superstructure is prestressed concrete T-shaped girder of simply supported span. The main size of the bridge pier is shown in Figure 3.

The element of SOLID70 is developed by ANSYS, which can be used to perform 3D steady-state thermal conductivity analysis and 3D transient thermal conductivity analysis. The element has 8 nodes and each node only has a temperature DOF. The SOLID70 is applied when temperature field analysis is performed. When constructing the FE model for the bridge pier, the element of SOLID45 is used, for this element has 6 DOFs at each node and can be used to account for the effects of plastic behavior, creep, expansion, stress stiffening, large deformation, and large strain.

The FE model is established as shown in Figure 4, which comprises 928 nodes and 513 elements.

The thermophysical parameters for the material of concrete are listed in Table 4.

The heat conductivity coefficient changes as the solar radiation intensity is different. And therefore different material properties are defined for the structure surfaces since 


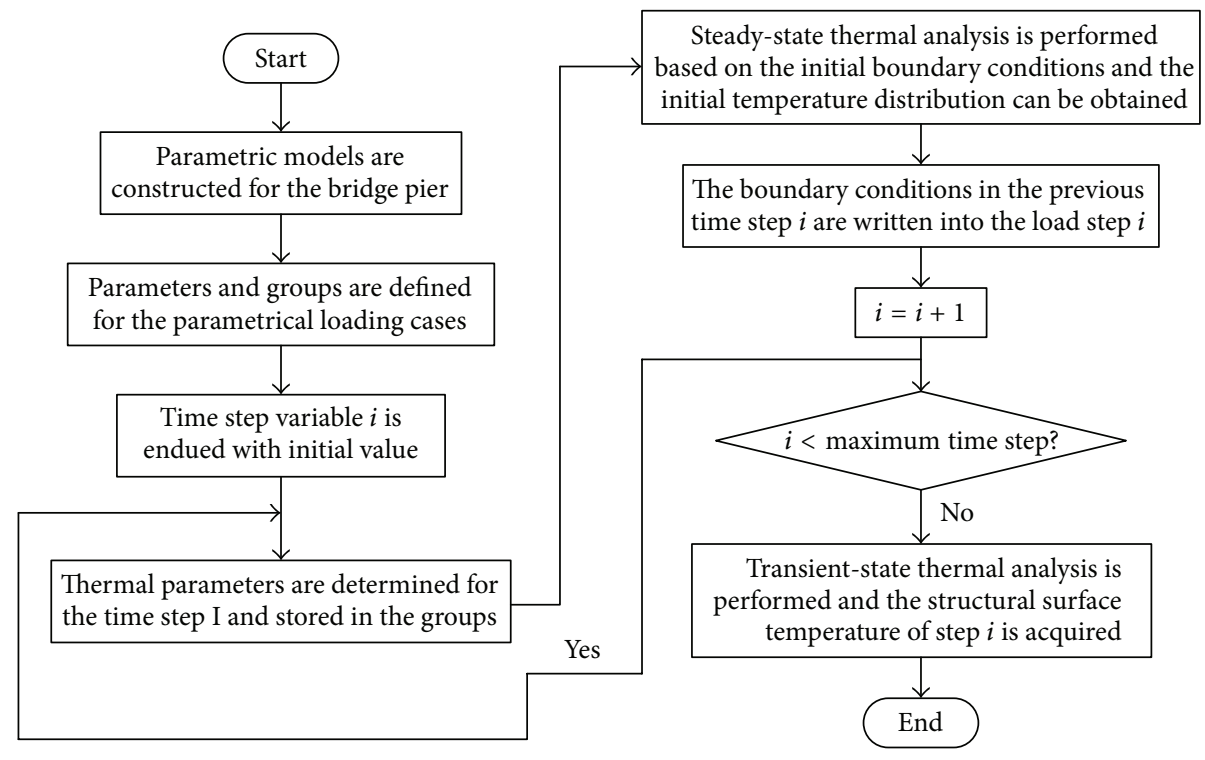

FIgURE 2: Flowchart of thermal field analysis.

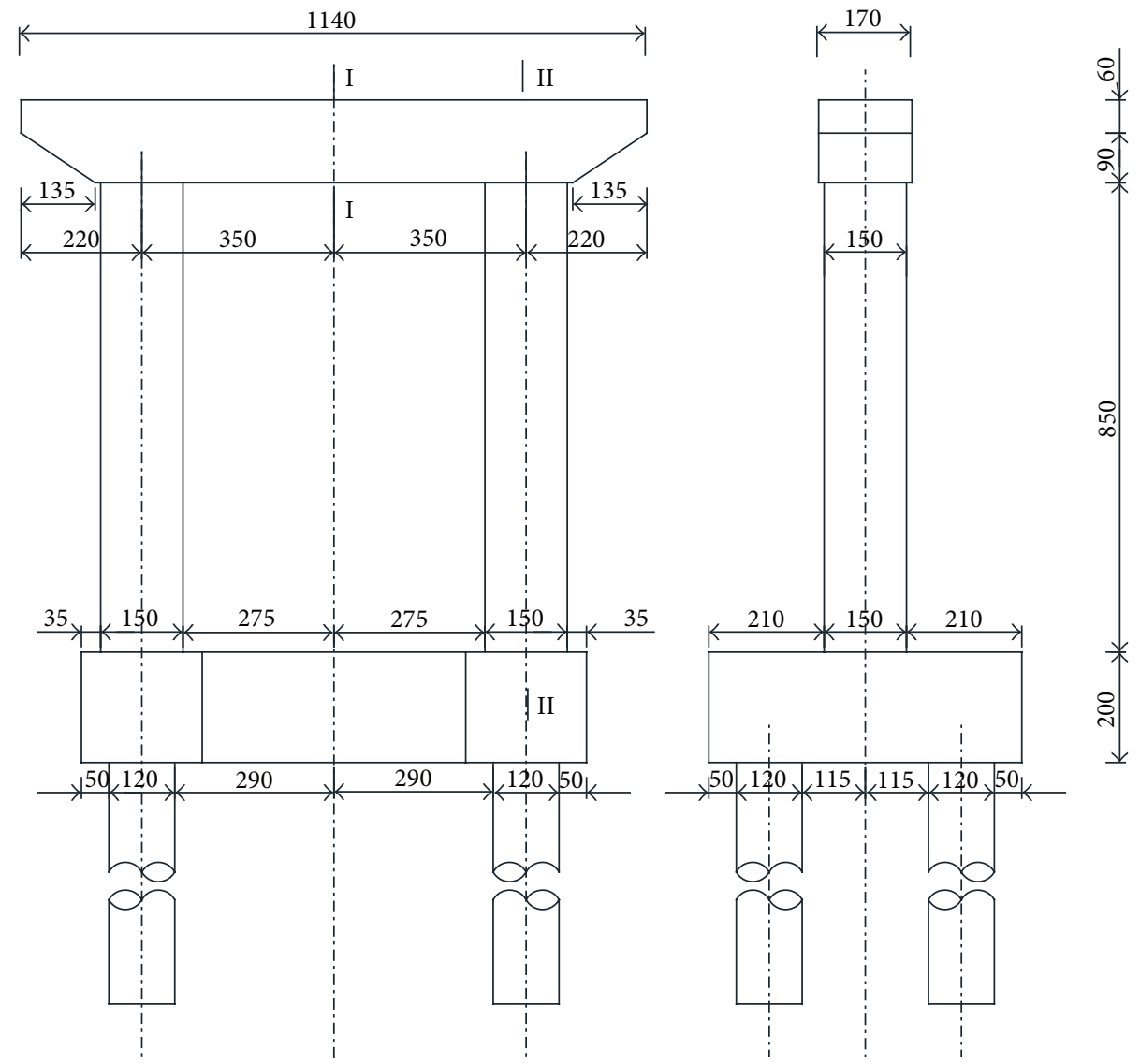

FIgURE 3: Dimensions of the bridge pier. 


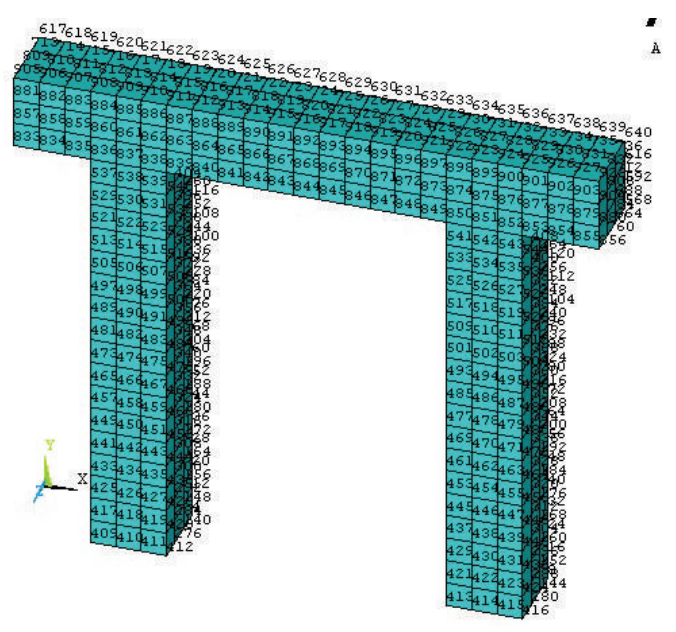

FIGURE 4: FE model of the bridge pier.

TABLE 4: Thermophysical parameters for concrete.

\begin{tabular}{lccc}
\hline Parameter & Unit & Variable name & Value \\
\hline Heat conductivity coefficient & $\mathrm{w} /\left(\mathrm{m} \cdot{ }^{\circ} \mathrm{C}\right)$ & $\mathrm{KXX}$ & 2.94 \\
Convection coefficient & $\mathrm{w} /\left(\mathrm{m} \cdot{ }^{\circ} \mathrm{C}\right)$ & $\mathrm{HF}$ & $11.0 / 11.5$ \\
Density & $\mathrm{kg} / \mathrm{m}^{3}$ & DENS & 2500 \\
Specific heat & $\mathrm{J} /\left(\mathrm{kg} \cdot{ }^{\circ} \mathrm{C}\right)$ & $\mathrm{C}$ & 1050 \\
Heat emission coefficient & $\mathrm{w} /\left(\mathrm{m}^{2} \cdot{ }^{\circ} \mathrm{C}\right)$ & $\mathrm{CONV}$ & 50 \\
\hline
\end{tabular}

some surfaces are exposed to the sunshine while the others are shadow surfaces.

\section{Construction of the FE Model and Calculation of the Temperature Field}

4.1. Calculation of the Distribution of the Temperature Field. Analysis is performed of temperature distribution in the pier structure at the time of 6:00 a.m. in the morning and 18:00 p.m. in the afternoon, respectively. The instantaneous sunlight direction is set to be in the $X-Y$ plane of the structural model. Except the structural surface which is exposed to the sunshine, the other surfaces are all applied with the boundary condition of air convection.

The results corresponding to three representative moments are chosen for analysis. At 8:00 a.m., the incident angle of the sunlight is small, the top surface of the cap beam and the surfaces of the pier exposed to the sun are influenced by solar radiation, and the FE model is modified according to this situation. At 11:00 a.m., a similar case can be expected with the situation at 8:00, with the exception that the area of the pier exposed to the sunshine decreases as the incident angle of the sunlight increases. When the time turns to $14: 30$ p.m., the calculation method remains unchanged for analysis of structural temperature field and temperature gradient stress compared with the cases of 8:00 and 11:00 a.m. But at this time, the incident angle of the sunlight reaches
TABLE 5: Calculated values of the structural surface temperature.

\begin{tabular}{lccccccc}
\hline \multicolumn{2}{l}{ Surface orientation } & \multicolumn{8}{c}{ Moment } \\
& $6: 00$ & $8: 00$ & $11: 00$ & $12: 30$ & $14: 30$ & $17: 00$ & $18: 00$ \\
\hline S & 13.41 & 17.43 & 35.38 & 37.81 & 39.20 & 28.61 & 20.64 \\
W (E) & 13.41 & 17.43 & 33.83 & 36.09 & 43.22 & 35.22 & 25.51 \\
N & 14.81 & 18.10 & 33.83 & 36.09 & 38.19 & 29.99 & 22.24 \\
H & 14.25 & 22.73 & 44.39 & 47.04 & 47.57 & 31.51 & 21.60 \\
\hline
\end{tabular}

the largest value in a day and the whole pier is located in the shadow of the cap beam; hence, the influence of solar radiation on the pier can be neglected. The temperature field nephogram for the bridge pier at different moments is shown in Figure 5.

The calculated values of temperature over the structural surfaces with different orientations at different moments are shown in Table 5.

4.2. Variation of the Temperature Gradient inside the Structure. Variation curves of the temperature gradient inside the structure with respect to the vertical axis are plotted corresponding to two typical sections I and II shown in Figure 3. The temperature values at the node in sections I and II are acquired at the moments of 8:00 a.m., 11:00 a.m., and 14:30 p.m., respectively, and are then fitted with curves as shown in Figures 6 and 7.

From Figures 6 and 7, it can be found that conduction of the thermal flux inside the column pier is evenly distributed, and no delamination is found of thermal conduction and structural forces at the interfaces between the different elements. Hence, it can conclude that the analytical method used in this paper is reasonable, and the temperature conduction and the temperature distribution at the structural nodes can be well captured. From the temperature curves inside the pier structure, it can be seen that the temperature distribution inside concrete structures coincides well with the temperature gradient curves defined in the Code for Design on Reinforced and Prestressed Concrete Structure of Railway Bridge and Culverts (TB10002.3-2005) [12]. This conclusion can also serve as a testimony that the method presented herein is rational.

\section{Analysis of the Calculated Results of the Structural Temperature Stress}

Transform the elements of thermal analysis into elements of structural analysis and write the temperature field information recorded in TEMP.rth from thermal analysis into the load step files. Then define the analytical type as static analysis and resolve the problem. After reanalysis of the FE model, the temperature stress at every time step can be derived.

With the use of solid elements in the FE model, result of structural stress can be obtained. From the stress result, it can be found that, in the solar radiation cases at the moments of 8:00 and 11:00 a.m., respectively, the stress of the two columns is not evenly distributed in the $X$ and $Y$ directions as 


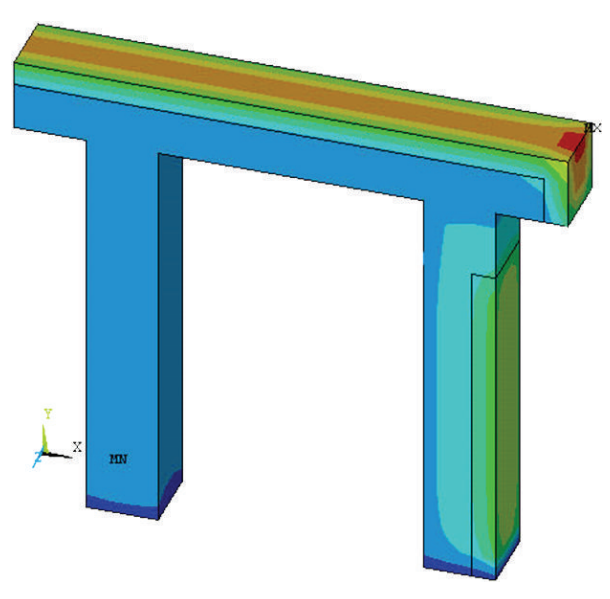

(a) 8:00 a.m.

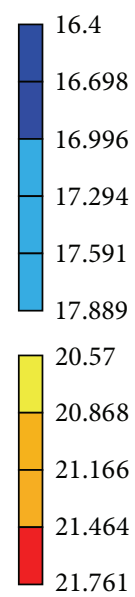

21.761

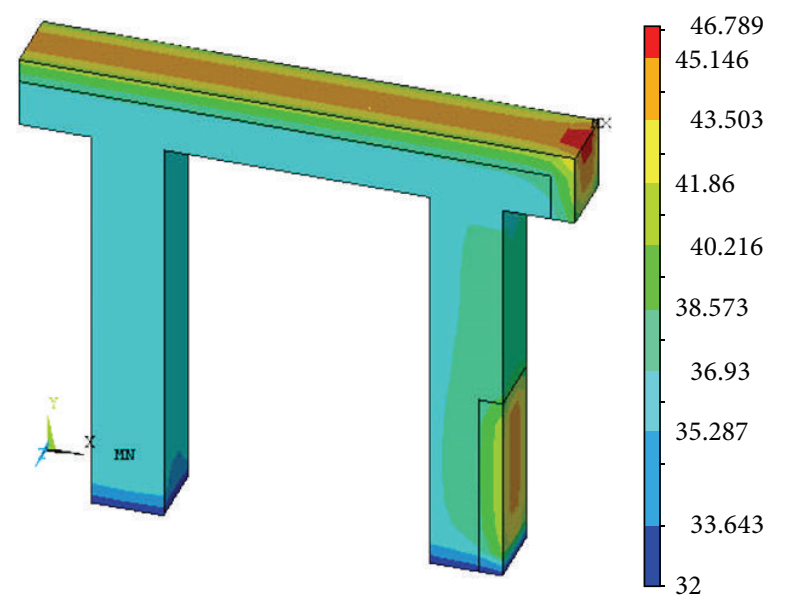

(c) 14:30 p.m.

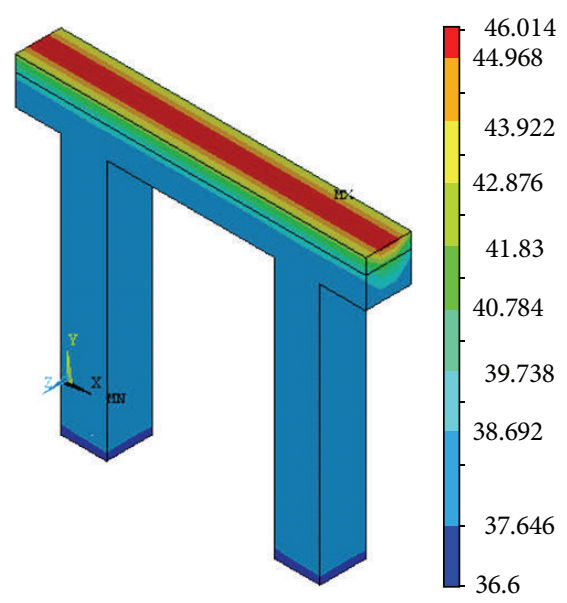

(b) 10:00 a.m.

FIgURE 5: Temperature field at each moment.

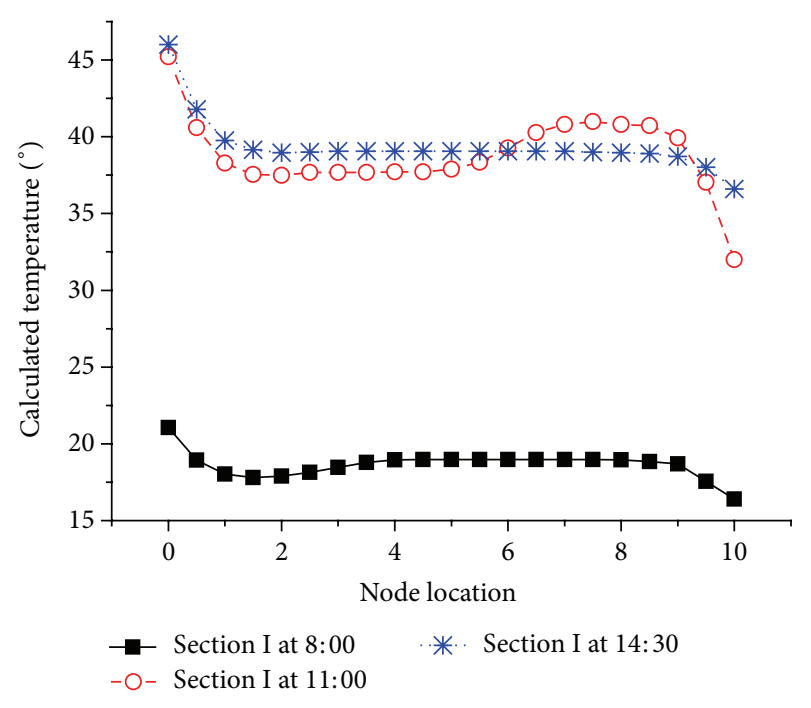

FIGURE 6: Temperature gradient of section I at the three moments.

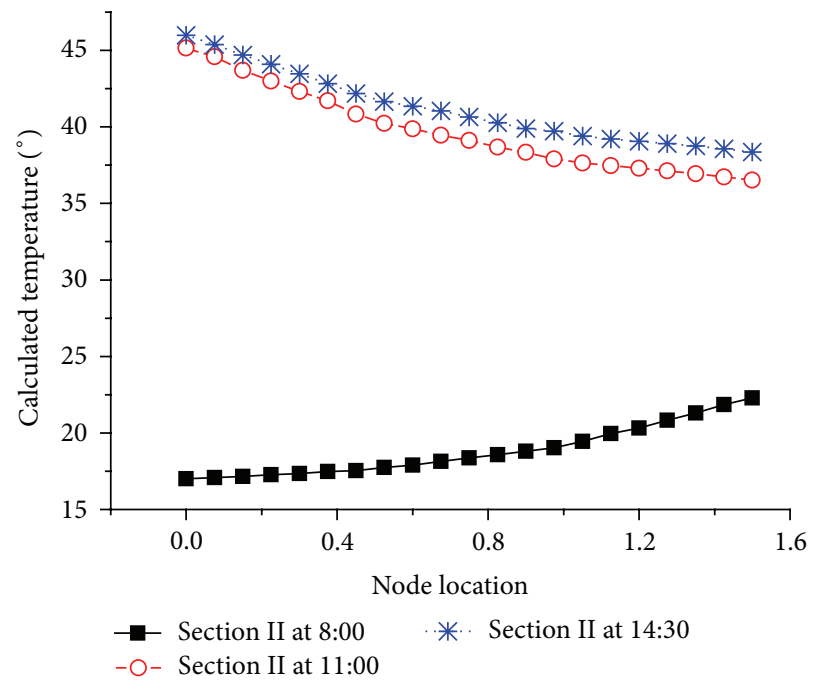

Figure 7: Temperature gradient of section II at the three moments. 


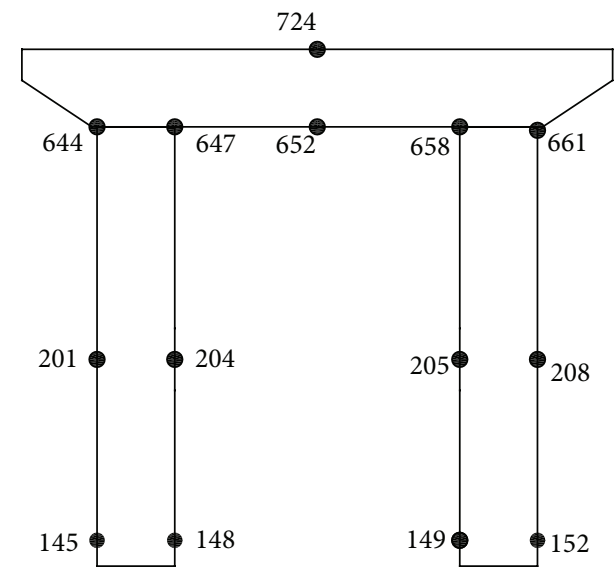

FIGURE 8: The nodes selected for stress analysis.

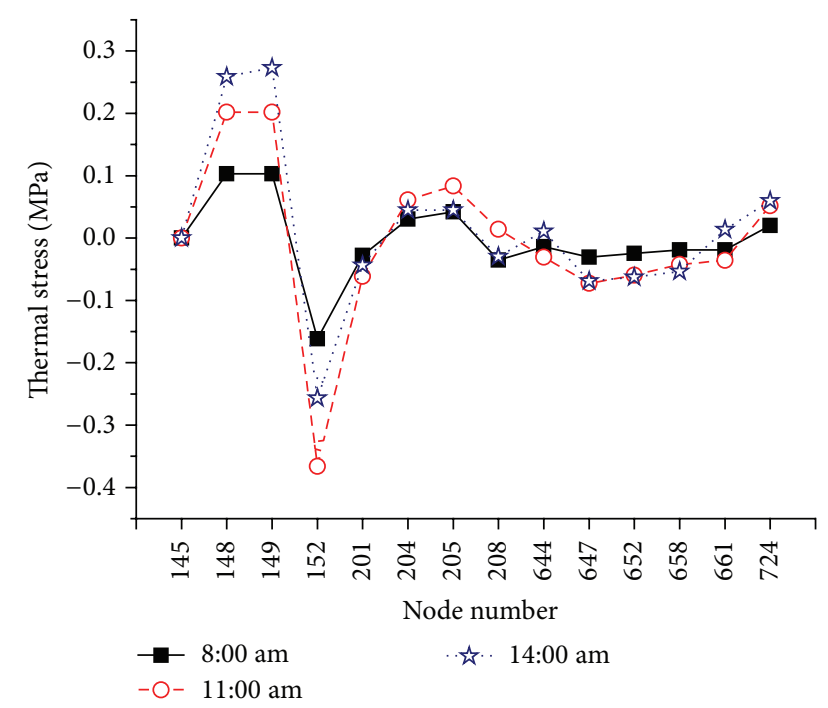

Figure 9: The thermal internal stress at the location of the selected nodes.

the solar radiation is not equally acting on the two columns. Some shear forces are generated in the cap beam because of solar radiation, which is detrimental to the pier structure. Because the load on the FE model is defined as increase of temperature, proof stress in the structure is mainly tensile. Under the three cases, all the maximum stress is found at the top surface of the cap beam, the reason of which is that the temperature difference here is the largest. It can also be found that considerable tensile stress is observed in the side surfaces of the columns and this tensile stress reaches its peak values at the moment of 14:30 p.m.

There is temperature difference on both the internal and external surfaces of the pier, and different distributions of tensile stress can be anticipated at different nodes of the same cross section. In order to better reflect this phenomenon, 14 typical nodes are selected in the pier model as shown in Figure 8, and the internal stress is shown in Figure 9.
It cannot be difficult to find that the tensile stress at nodes 148 and 149 is the largest. Some tensile stress can also be found at the other nodes; although small in values, they can lead to much worse damage under the repeated solar radiation, for there is usually no prestressing steel mounted in the bridge pier. So much more attention is needed to be paid to the solar radiation influence on column pier, so that the unnecessary damage can be avoided in the bridge substructure.

\section{Conclusions}

A method is proposed in this paper for analysis of the temperature field and the temperature stress of the bridge substructure under solar radiation. Using the software of ANSYS, thermal analysis is performed for a dual-column pier under the solar radiation of different incident angles corresponding to the different moments from 6:00 a.m. to 18:00 p.m. The results corresponding to three typical moments are selected for presentation, and the temperature stress of the pier structure is analyzed based on thermal analysis. The following conclusions can be drawn.

(1) It can be found that the conduction of the thermal flux inside the structure is uniformly distributed, and the temperature distribution coincides quite well with the temperature gradient curves defined in the design codes, which can be served as a testimony that the method presented in this paper is reasonable.

(2) After comparing the results of the two cases in accordance with 11:00 a.m. and 14:30 p.m., respectively, it can be concluded that the amounts of solar radiation absorbed by the structure as well as the surficial location of the structure exposed to the sunshine are the two key factors which are most efficient in controlling the distribution of temperature difference stress.

(3) The tensile stress which is most hazardous to the safety of bridge structures can be found in the corners of the bridge piers, with the largest value of about $0.3 \mathrm{MPa}$. The repeated and accumulative characteristics of the solar radiation effect can lead to an unpredictable potential safety hazard to the bridges. And hence it is highly suggested that the structural stress induced by solar radiation should be considered during the design and construction of a column pier with large size.

\section{Conflict of Interests}

The authors declare that there is no conflict of interests regarding the publication of this paper.

\section{References}

[1] J. R. Zhang, "A test study on the solar radiation absorption coefficient of concrete surface," Building Science, vol. 22, no. 6, pp. 42-45, 2006.

[2] F. Kehlbeck, Effect of Solar Radiation on Bridge Structures, translated by: X. F. Liu, China Railway Publishing House, Beijing, China, 1981. 
[3] F. A. Branco and P. A. Mendes, "Thermal actions for concrete bridge design," Journal of Structural Engineering, vol. 119, no. 8, pp. 2313-2231, 1993.

[4] G. Zhou and T. Yi, "Thermal load in large-scale bridges: a stateof-the-art review," International Journal of Distributed Sensor Networks, vol. 2013, Article ID 217983, 17 pages, 2013.

[5] A. Saetta, R. Scotta, and R. Vitaliani, "Stress analysis of concrete structures subjected to variable thermal loads," Journal of Structural Engineering, vol. 121, no. 3, pp. 446-457, 1995.

[6] M. M. Elbadry and A. Ghali, "Temperature variations in concrete bridges," Journal of Structural Engineering, vol. 109, no. 10, pp. 2355-2374, 1983.

[7] G. J. Wei, "Research for temperature fields and temperature stresses of prestressed concrete single-box girder bridge," Journal of Southwest Jiaotong University, vol. 4, no. 89, pp. 12-16, 1989.

[8] L. L. Zhang, Y. Q. Zhao, and L. Yang, "Analysis of solar radiation thermal stress of concrete box girders based on ANSYS," Journal of Computer Applications, vol. 6, pp. 177-180, 2011.

[9] E. Mirambell and A. Aguado, "Temperature and stress distributions in concrete box girder bridges," Journal of Structural Engineering, vol. 116, no. 9, pp. 2388-2409, 1990.

[10] S. C. Deng, "Study on heat transfer cofficient of concrete temperature field and architecture exterior wall in thermodynamics," Journal of Huizhou University (Natural Science Edition), vol. 29, no. 9, pp. 5-14, 2009.

[11] N. Tang, "Simulation on time-varying temperature felds of the concrete roof," Journal of Wuhan University of Technology, vol. 33, no. 11, pp. 73-77, 2011.

[12] Ministry of Transport of the People's Republic of China, Code for Design on Reinforced and Prestressed Concrete Structure of Railway Bridge and Culvert, China Railway Publishing House, Beijing, China, 2005. 


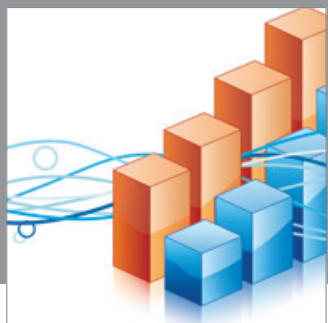

Advances in

Operations Research

mansans

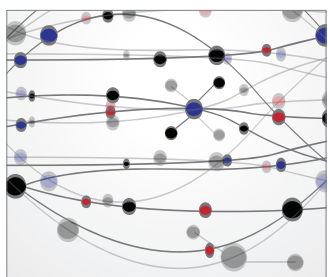

The Scientific World Journal
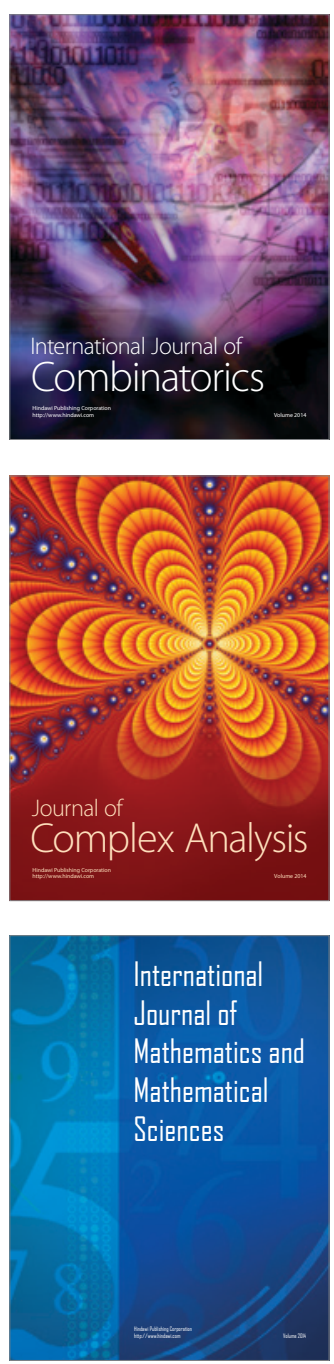
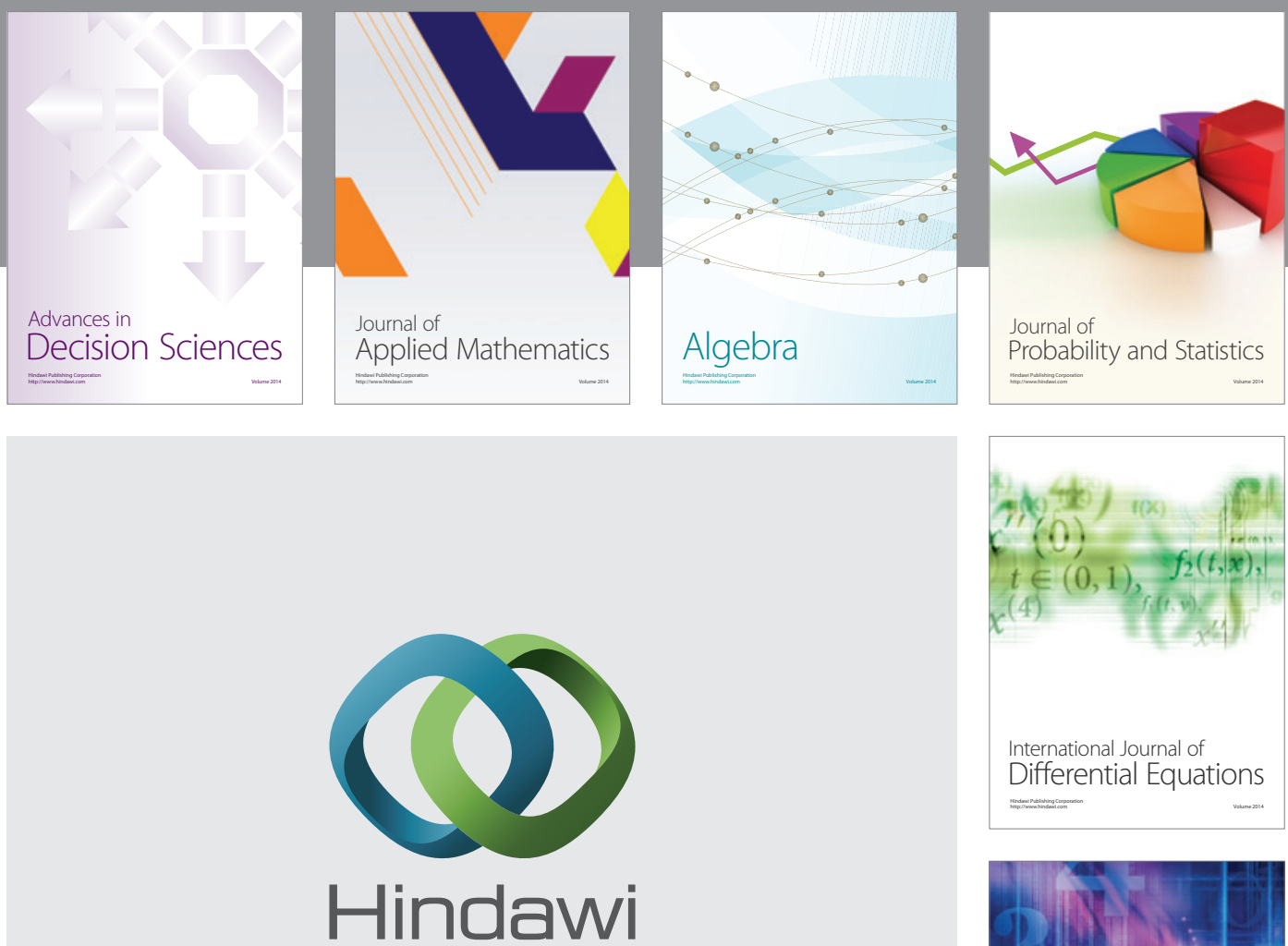

Submit your manuscripts at http://www.hindawi.com
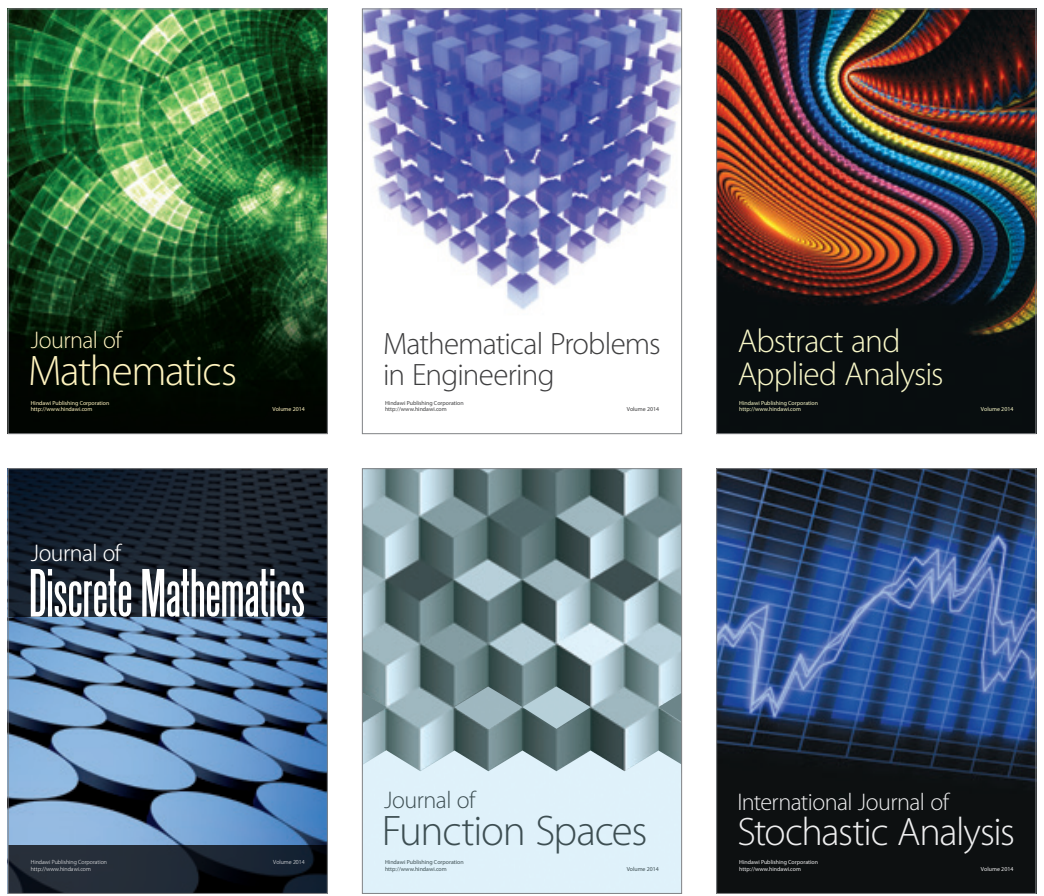

Journal of

Function Spaces

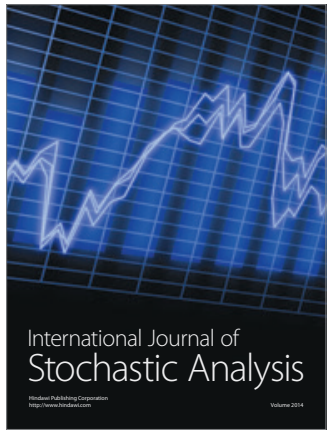

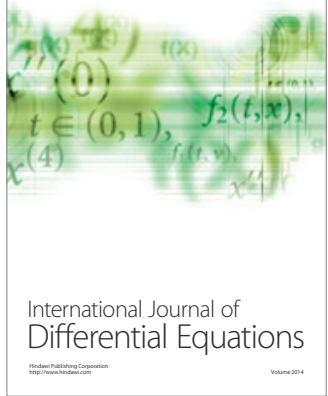
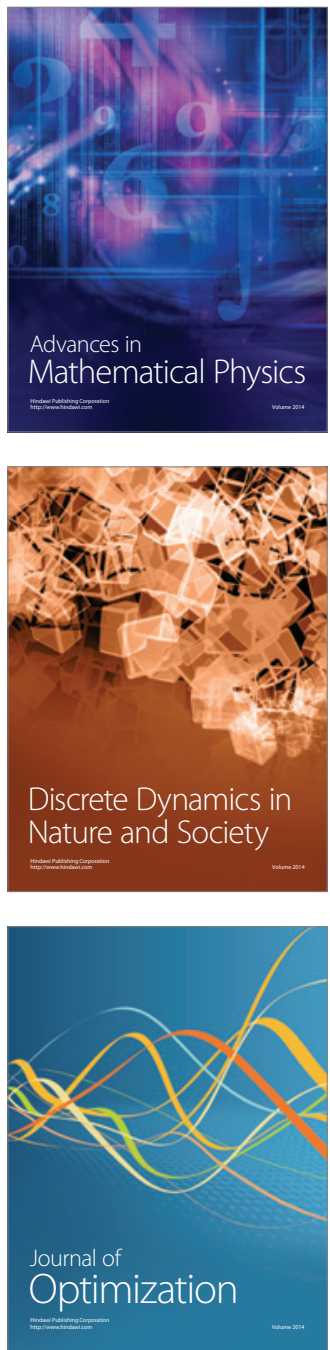